\title{
A multi-country outbreak of Salmonella Newport gastroenteritis in Europe associated with watermelon from Brazil, confirmed by whole genome sequencing: October 2011 to January 2012
}

L Byrne (lisa.byrne@phe.gov.uk) ${ }^{1}$, I Fisher ${ }^{1}$, T Peters², A Mather ${ }^{3}$, N Thomson³, B Rosner ${ }^{4}$, H Bernard ${ }^{4}$, P McKeown $^{5}$, M Cormican $^{6}$, J Cowden 7 , V Aiyedun ${ }^{1}$, C Lane $^{1}$, on behalf of the International Outbreak Control Team ${ }^{8}$

1. Gastrointestinal, Emerging and Zoonotic Infections, Centre for Infectious Disease Surveillance and Control, Public Health England, Colindale, London, United Kingdom

2. Gastrointestinal Bacteria Reference Unit, Centre for Infectious Disease Surveillance and Control, Public Health England, Colindale, London, United Kingdom

3. Wellcome Trust Sanger Institute, Wellcome Trust Genome Campus, Hinxton, Cambridge, United Kingdom

4. Robert Koch Institute, Department for Infectious Disease Epidemiology, Berlin, Germany

5. Health Protection Surveillance Centre, Dublin, Ireland

6. National Salmonella, Shigella, Listeria Reference Laboratory, Galway University Hospital, Newcastle Road, Galway, Ireland

7. Health Protection Scotland, Glasgow, United Kingdom

8. The members of the team are listed at the end of the article.

Byrne L, Fisher I, Peters T, Mather A, Thomson N, Rosner B, Bernard H, McKeown P, Cormican M, Cowden J, Aiyedun V, Lane C, on behalf of the International Outbreak Control Team. A multi-country outbreak of Salmonella Newport gastroenteritis in Europe associated with watermelon from Brazil, confirmed by whole genome sequencing: October 2011 to January 2012. Euro Surveill. 2014;19(31):pii=20866. Available online: http://www.eurosurveillance.org/ViewArticle. aspx?Articleld $=20866$

In November 2011, the presence of Salmonella Newport in a ready-to-eat watermelon slice was confirmed as part of a local food survey in England. In late December 2011, cases of $S$. Newport were reported in England, Wales, Northern Ireland, Scotland, Ireland and Germany. During the outbreak, 63 confirmed cases of $S$. Newport were reported across all six countries with isolates indistinguishable by pulsed-field gel electrophoresis from the watermelon isolate. A subset of outbreak isolates were whole-genome sequenced and were identical to, or one single nucleotide polymorphism different from the watermelon isolate. In total, 46 confirmed cases were interviewed of which 27 reported watermelon consumption. Further investigations confirmed the outbreak was linked to the consumption of watermelon imported from Brazil. Although numerous Salmonella outbreaks associated with melons have been reported in the United States and elsewhere, this is the first of its kind in Europe. Expansion of the melon import market from Brazil represents a potential threat for future outbreaks. Whole genome sequencing is rapidly becoming more accessible and can provide a compelling level of evidence of linkage between human cases and sources of infection, to support public health interventions in global food markets.

\section{Introduction}

On 28 November 2011, as part of a local food survey, Public Health England (PHE; formerly the Health Protection Agency) Food Water and Environment (FWE) Laboratory in Preston, England, confirmed the presence of Salmonella in a ready to eat watermelon slice purchased from a major supermarket retailer. The isolate was sent to the Gastrointestinal Bacteria Reference Unit (GBRU) at Colindale, London who reported it as Salmonella enterica subspecies enterica serovar Newport on 6 December 2011. On 13 December 2011, the result was communicated through the Rapid Alert System for Food and Feed (RASFF) of the European Commission [1].

In late December 2011, Health Protection Scotland (HPS) reported four cases of S. Newport, all with the same pulsed-field gel electrophoresis (PFGE) profile which had not previously been seen. Concurrently in England, Wales and Northern Ireland, reporting of $S$. Newport infections exceeded expected levels. Molecular analysis of isolates from the human cases from all four countries indicated a PFGE profile indistinguishable from the sliced watermelon isolate.

On 13 January 2012, Germany reported through the Epidemic Intelligence Information System (EPIS) at the European Centre of Disease Prevention and Control (ECDC) fourteen $S$. Newport isolates that were indistinguishable from the PFGE profile of the sliced watermelon isolate. Four cases with this profile were also reported in Ireland in January 2012.

A multi-agency outbreak control team (OCT) was convened on 16 January 2012 comprising staff from PHE, Public Health Wales (PHW), HPS and the United Kingdom (UK) Food Standards Agency (FSA). There 
were separate communications with the Robert Koch Institute (RKI) regarding the German cases and with the Health Protection Surveillance Centre (HPSC) and the National Salmonella, Shigella and Listeria Reference Laboratory (NSSLRL) regarding cases from Ireland. German and Irish public health and food safety authorities subsequently joined the OCT.

The aims of investigations were to gather and collate information on exposures, to identify the potential source(s), to institute immediate control measures and to determine if there were any lessons to be learnt regarding future prevention.

We describe an outbreak of $S$. Newport across six countries linked to the consumption of watermelon originating from Brazil.

\section{Methods}

\section{Epidemiological investigations}

\section{Case ascertainment}

Surveillance data from each of the six countries were reviewed for 2011. Exceedances in S. Newport cases were detected in December 2011. Therefore it was decided to perform pulsed-field gel electrophoresis (PFGE) analysis on all $S$. Newport cases identified from 31 October 2011 onwards to account for any outbreak cases that might have arisen in the weeks prior to the exceedance indicator being triggered.

\section{Case definition}

Outbreak cases were defined as persons with: (i) laboratory-confirmed infection with fully antimicrobial-sensitive $S$. Newport exhibiting the outbreak PFGE profile designated as SNEWXB.0110 (defined by the watermelon isolate); (ii) symptoms including diarrhoea or any two or more of: vomiting, fever or abdominal pain; (iii) onset of illness between 31 October 2011 and 31 January 2012; and (iv) who was reported in any of the six countries.

\section{Food-borne illness questionnaire}

In England, Wales and Northern Ireland, upon notification of Salmonella cases to PHE centre's (PHEC's), cases are routinely followed up by the PHEC and Environmental Health Officers (EHOs) in local authorities; Cases were contacted and asked to complete either the Salmonella or the generic food-borne illness questionnaire. While questionnaire formats varied between local authorities, all sought information on clinical, travel and food history in the seven days before illness. Specific questions around fruit consumption were not included. During the outbreak completed questionnaires were returned to epidemiologists in the Gastrointestinal, Emerging and Zoonotic Infections Department (GEZI), $\mathrm{PHE}$, Colindale, where they were reviewed to elucidate commonality of exposures between cases.
Outbreak case exposure questionnaire

Following the first OCT meeting on 16 January 2012, a questionnaire was designed to collect information specifically on fruit consumption and was shared with each member country of the OCT. The questionnaire gathered detailed information on consumption of different types of fruit, including melon, and addressed whether products were pre-packaged, sliced, cubed, mixed with other fruit and where they were purchased and consumed. Cases in England, Wales, Northern Ireland and Ireland were interviewed by designated investigators using the bespoke questionnaire. Cases were not followed up if contact details were unobtainable. Attempted contact was made on a maximum of five occasions, at which point they were designated as being lost to follow-up.

The same questionnaire was used for cases in England, Wales, Northern Ireland and Ireland to interview cases. In Scotland, the questionnaire was completed retrospectively by investigators at HPS using information collected in interviews with EHOs. In Germany, cases were interviewed using a translation of the questionnaire supplied by the UK OCT with additional, more detailed questions on food history in the three days before disease onset.

Analytical comparison of watermelon consumption To estimate the frequency of watermelon consumption in a group of persons in Germany unaffected by $S$. Newport infection, staff members included in the official mailing list of one of the RKI departments were invited via email to participate in an ad-hoc survey on 25 January 2012. The survey included the question whether any watermelon had been consumed in December 2011. The proportion of persons reporting watermelon consumption among interviewed outbreak cases (in the three days before symptom onset) and among RKI department staff members were compared. Odds ratios (OR) and corresponding 95\% confidence intervals $(\mathrm{Cl})$ were calculated and statistical significance ( $p<0.05$ ) was evaluated using Fisher's exact test. Data analysis was performed using Stata 12 (Stata Corporation, College Station, United States).

In the UK, the FSA extracted data on watermelon consumption from the UK National Diet and Nutrition Survey dataset for comparison with cases [2]. UK case consumption data were insufficient to support statistical analyses.

\section{Microbiological investigations}

Isolates from patients and food samples were characterised and compared. In England, Wales and Northern Ireland, all isolates were sent to GBRU; isolates in Scotland to the Scottish Salmonella, Shigella, and Clostridium Difficile Reference Laboratory; in Ireland to the NSSLRL and in Germany to the National Reference Centre for Salmonella and other Bacterial Enteric Pathogens at the RKI, Wernigerode. 
All isolates were serotyped according to the WhiteKauffmann-LeMinor scheme [3]. Antimicrobial resistance profiles were determined by testing against a routine panel of antimicrobials in each Reference Laboratory. Each reference laboratory tested for ampicillin, cefotaxime, chloramphenicol, ciprofloxacin, gentamicin, kanamycin, nalidixic acid, streptomycin, tetracyclines and trimethoprim/trimethoprim-sulfamethoxazole resistance as well as a range of additional antibiotics depending on the participating laboratory. Cut-off values according to the European Committee on Antimicrobial Susceptibility Testing (http://www.eucast.org) were used in Germany and Ireland. For isolates received by GBRU and in the Scottish reference laboratory, cut-off values were used as previously described on the basis of long-term studies [4-5].

PFGE using the PulseNet-Europe/Salm-gene protocol was performed on all $S$. Newport isolates from patients with an onset of illness date reported during the outbreak period (31 October 2011 to 31 January 2012) [6]. The PFGE profile from the watermelon isolate was designated the outbreak profile (SNWPXB.0110). Comparisons between profiles were analysed using algorithms within the BioNumerics software package (version 6.10; Applied Maths, Sint-Martens-Latem, Belgium). Dendrograms were constructed using the
Dice similarity coefficient and the unweighted pair group method with arithmetic averages (UPGMA). The PFGE images of the outbreak strain were shared with PulseNet US and PulseNet Latin America. The results of PFGE analysis together with antimicrobial resistance profiles were used to inform case definitions.

A subset of isolates from UK cases were selected for whole genome sequencing (WGS). This included 24 of 37 outbreak isolates from UK cases and the isolate from the watermelon slice. An additional 11 nonoutbreak isolates were selected for comparison. Genomic DNA was extracted using the Wizard Genomic DNA Purification Kit (Promega), and samples were sequenced using multiplex libraries on the HiSeq platform (Illumina) using $100 \mathrm{bp}$ paired-end reads. The sequence data were aligned to the reference strain S. Newport SL254 (hereafter, SL254) along with its associated plasmids pSL254-3 and pSN254 (accession numbers CPoo1113, CPoo1112 and CPooo604, respectively) using SMALT vo.6.4 [7]. Single nucleotide polymorphisms (SNPs) was compared to the reference strain and a maximum likelihood phylogeny of the isolates was constructed using RAxML [8-9]. A high divergence between the outbreak isolates and the reference SL254 was observed, with ca 50,600 SNPs separating the outbreak isolates from the reference SL254. To improve resolution, the outbreak isolates,

\section{FIGURE 1}

Epidemic curve based on onset week ${ }^{\mathrm{a}}$ of confirmed Salmonella Newport outbreak cases ${ }^{\mathrm{b}}$ in the United Kingdom, Ireland and Germany, 31 October 2011-22 January $2012(\mathrm{n}=61)$

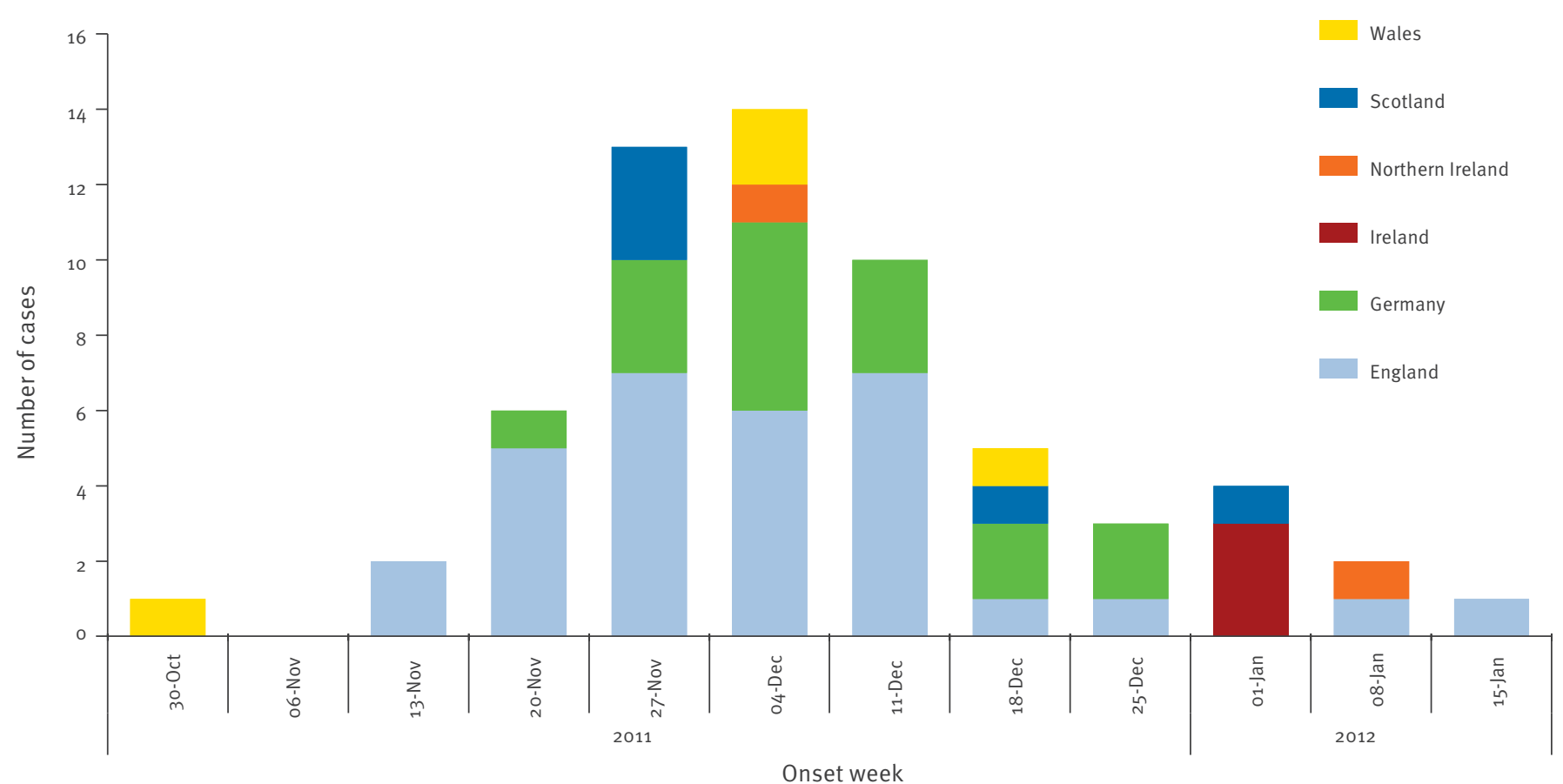

a For two cases in Wales and one in England, onset date was not known and specimen date was used.

b Excludes one asymptomatic case from Ireland and one German case where neither onset nor specimen date were reported. In total, 61 confirmed cases are included. 
along with four non-outbreak isolates used as outliers, were re-mapped against the unordered assembly of the sliced watermelon isolate. De novo assembly of the watermelon isolate was undertaken using Velvet with a k-mer of 61 , without scaffolding, giving an $\mathrm{N}_{50}$ of 301,843 and 192 nodes [10].

\section{Traceback investigations}

Following isolation of $S$. Newport from the watermelon slice, the FSA undertook product traceback. The Food Safety Authority of Ireland (FSAI) also performed traceback investigations into the source of watermelon consumed by a family cluster.

In Germany, traceback investigations were coordinated at the federal level by the Federal Institute for Risk Assessment (Bundesinstitut für Risikobewertung $(B f R)$ ). They started from five supermarket branches of one chain, where cases had purchased watermelons. Information on the immediate provider of watermelons was obtained through delivery documents provided by the stores to local veterinary offices. Watermelon deliveries were then further traced back stepwise by the federal states authorities and the BfR. The distribution chain was determined to originate from a single watermelon distributor in the Netherlands. The Federal Office of Consumer Protection and Food Safety (Bundesamt für Verbraucherschutz und Lebensmittelsicherheit, $(\mathrm{BVL}))$ in Germany then contacted food safety authorities in the Netherlands to obtain further information on the origin of the watermelons distributed by the Dutch company.

\section{Results}

\section{Epidemiological investigations}

\section{Outbreak description}

Between all six countries a combined total of 63 confirmed outbreak cases were reported with onset dates during the outbreak period (31 October 2011 to 31 January 2012): 31 in England, four in Wales, two in Northern Ireland, five in Scotland, four in Ireland, and 17 in Germany.

Onset dates ranged from 5 November 2011 to 19 January 2012, with almost half $(29 / 61)$ of these between the 28 November and 11 December 2011 (Figure 1).

Cases were predominantly female (45/63) and ranged in age from six months to 95 years, with the greatest number (15/63) in children aged five years or less. In England, Wales and Northern Ireland, cases were distributed across all regions, with a predominance of cases in the east (7/37) and south-west (5/37) of England. In Germany, cases were reported from seven federal states across the country.

In total, 14 cases were hospitalised: three in England, two in Wales, one in Ireland and eight in Germany. There were three fatalities: one in England (aged 56
TABLE

Reporting of watermelon consumption among confirmed cases of Salmonella Newport of the outbreak profile interviewed in the United Kingdom, Ireland and Germany, 31 October 2011-22 January $2012(n=63)$

\begin{tabular}{|l|c|c|c|}
\hline Country & $\begin{array}{c}\text { Number of } \\
\text { outbreak } \\
\text { cases }\end{array}$ & $\begin{array}{c}\text { Number } \\
\text { of cases } \\
\text { interviewed }\end{array}$ & $\begin{array}{c}\text { Reported } \\
\text { watermelon } \\
\text { consumption }\end{array}$ \\
\hline England & 31 & 19 & 13 \\
\hline Scotland & 5 & 4 & 4 \\
\hline Wales & 4 & 4 & 0 \\
\hline Northern Ireland & 2 & 2 & 1 \\
\hline Ireland & 4 & 4 & 3 \\
\hline Germany & 17 & 13 & 6 a \\
\hline All countries & 63 & 46 & $\mathbf{2 7}$ \\
\hline
\end{tabular}

a Two additional cases reported 'possible' consumption of watermelon.

years) and two in Germany (aged 92 and 95 years); all three had underlying health conditions (cancer or cardiovascular disease).

Case exposures

In England, Wales and Northern Ireland, completed EHO questionnaires were received for 22 of 37 confirmed cases, including 11 who reported consumption of fruit and one who specified melon.

In total, 46 of 63 confirmed cases were interviewed using the outbreak case exposure questionnaire, including 19 cases from England, four from Wales, two from Northern Ireland four from Scotland, four from Ireland and 13 from Germany (Table). Of the remaining 17 cases not interviewed, three were deceased, five did not respond, contact details were unavailable for six, two refused consent to be interviewed and one had an onset date in early November and was not followed up due to the long time period which had elapsed.

Consumption of pre-packed, pre-sliced or whole watermelon was reported by $59 \%$ of interviewed cases. In Ireland, three of the four cases were a family cluster who reported purchasing a whole melon which they sliced and consumed at home. The fourth case had no history of watermelon consumption.

An additional two cases in Germany reported possible consumption of watermelon. The remaining fifteen cases reported no consumption of watermelon, two of them reported consumption of other types of melon (Galia and Cantaloupe).

In follow-up interviews with cases from England and Northern Ireland, retailer information was reported for 21 confirmed cases. All four of the largest UK supermarket retailers were reported as well as independent green grocers, and their proportions were largely 
Representative pulsed-field gel electrophoresis profile of Salmonella Newport isolates from confirmed outbreak cases ( $\mathrm{n}=4$ ) and the watermelon sample, United Kingdom, Ireland and Germany, 31 October 2011-22 January 2012

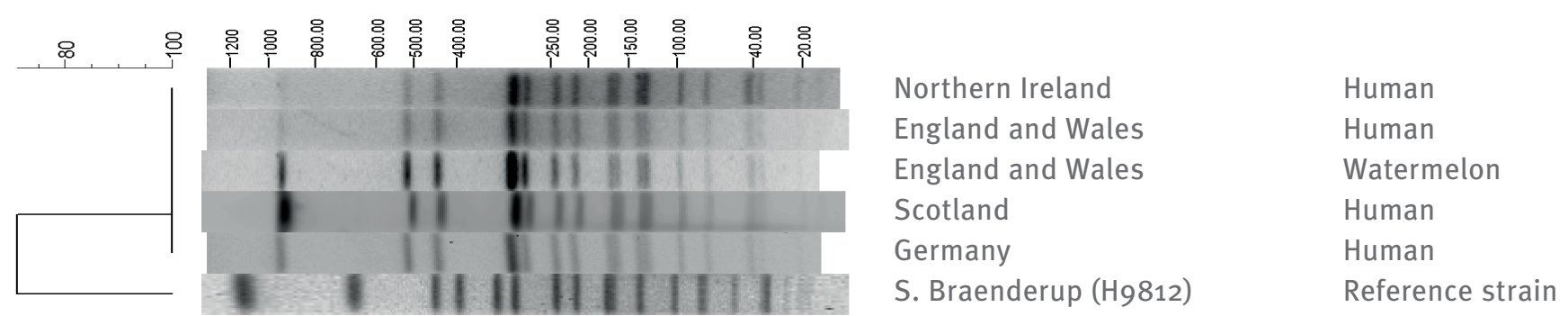

reflective of their market shares. In Scotland, one other retailer was cited by consumers, which was not reported by cases elsewhere in the UK. The German cases with confirmed watermelon consumption reported five different branches of one supermarket chain where they had purchased watermelon which was sliced in store.

Analytical comparison of watermelon consumption Of 168 persons included in the RKI department staff emailing list, 91 (54\%) replied. Of the persons who could remember whether they had consumed watermelon $(n=87)$, seven $(8 \%)$ affirmed consumption. This compares to $46 \%(6 / 13)$ of the German cases interviewed who remembered watermelon consumption (Table) and corresponds to an OR of 9.8 (95\% Cl: $2.6-$ 37.3, two-sided $p$ value <0.01).

Data on watermelon consumption extracted from the 2008-10 UK National Diet and Nutrition Survey dataset indicated that the level of reported watermelon consumption in the UK is normally $5-10 \%$ [9]. Consumption reported by cases (64\%) was therefore considerably higher than would be expected in the general population.

\section{Microbiological investigations}

A single strain of $S$. Newport was found to be involved in this outbreak, with the novel PFGE profile SNWPXB.0110 (Figure 2). Retrospective analysis of $S$. Newport isolates detected in cases in England and Wales $(n=91)$ before the outbreak period revealed no isolates with the same profile. Furthermore, no matches were found to this profile in PulseNet US or Latin America databases. All isolates were fully susceptible to the antimicrobials tested. WGS revealed identical sequences between the watermelon isolate and 19 of the 24 sequenced outbreak isolates from the UK. The remaining five sequenced isolates differed from the watermelon isolate by just one SNP. The non-outbreak strains differed by several thousand SNPs (Figure 3).

Traceback

In the UK, product follow-up of the contaminated watermelon slice indicated the product originated from a batch of watermelons imported from Brazil with a useby date of 25 November 2011. The watermelons from which the slice was produced had been supplied whole to a major UK processor where they were sliced, packaged and distributed. Salmonella was not detected in subsequent raw material or packed product that was sampled at the processor's premises. As the useby date of the affected batch had expired before the detection of $S$. Newport infections, no action could be taken to recall or withdraw the product. Further investigations were undertaken following human cases in Scotland in late December 2011. The confirmed cases in Scotland reported a different retailer from the one implicated in November, and traceback indicated a separate supply chain which did not involve the same UK processor. However, the melons were sourced from the same region in Brazil but from a different grower.

The FSAI performed a traceback on the watermelon consumed by the family cluster in Ireland. It had arrived in a shipment from Brazil and further work traced it back to the same source as the watermelon slice found positive for the outbreak strain in November 2011. The watermelons had been harvested on 25 October 2011, dispatched on 31 October 2011 and arrived in Dublin on 21 November 2011. The entire consignment was distributed between 1 December and 31 December 2011, consistent with the latest onset date in early January 2012. No action was necessary as the implicated product was no longer on sale in Ireland.

German authorities traced back watermelons from five supermarket branches of one chain where cases had reported purchasing watermelon, to a distributor in the Netherlands. From there, watermelons were traced back to the same grower in Brazil associated with the contaminated watermelon slice and the Irish cases and to an affiliated grower working together in a co-operative in the same geographical region in Brazil.

\section{Discussion}

Molecular, epidemiological, and traceback investigations identified a multi-country outbreak of $S$. Newport 


\section{FIGURE 3}

Phylogeny of Salmonella Newport isolates from the sliced watermelon, confirmed outbreak cases (n=24) and non-outbreak cases ( $n=4)$, United Kingdom, Ireland and Germany, 31 October 2011-22 January 2012

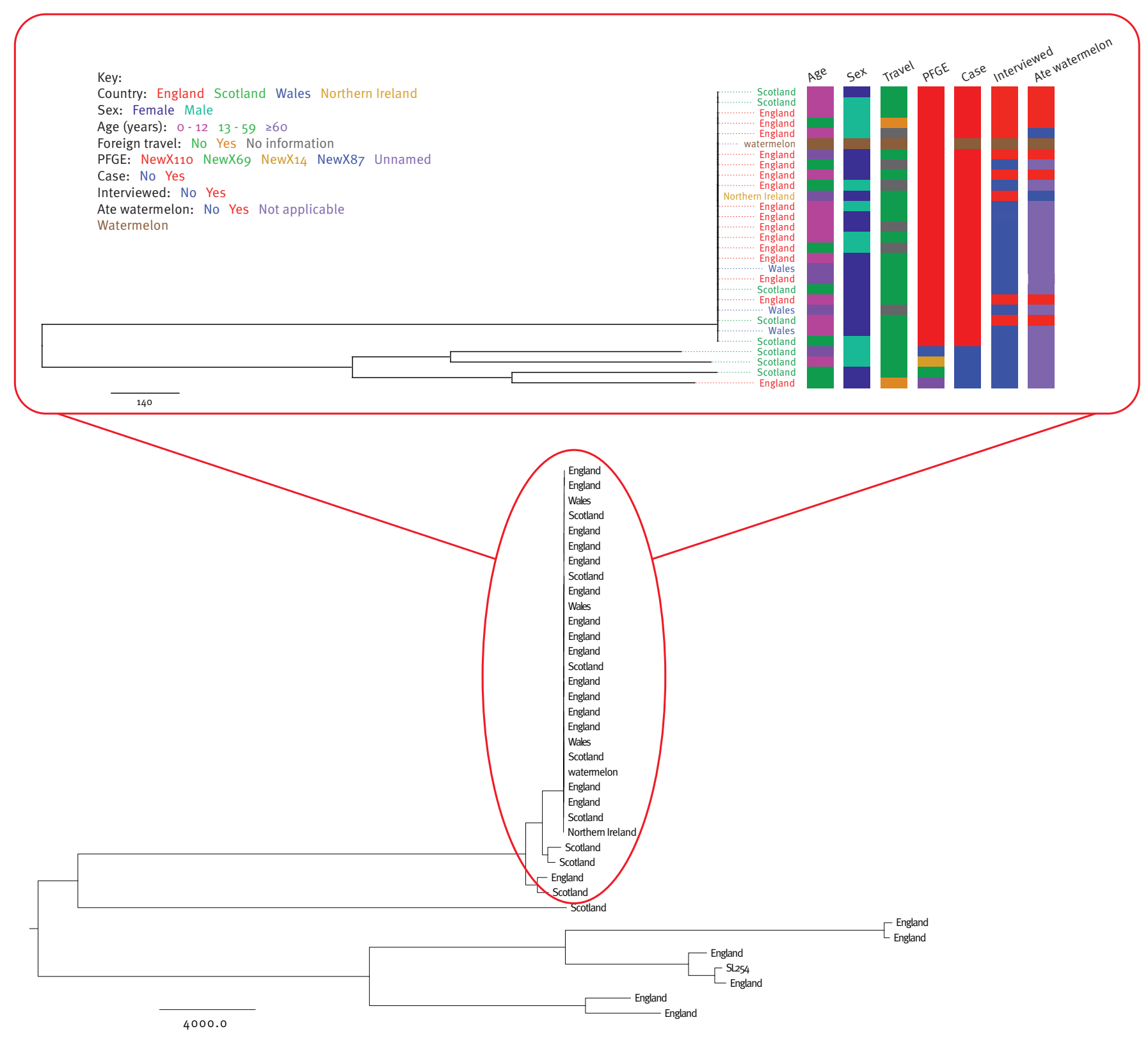

S. Newport cases mapped to reference sequence SL254.

Inset: isolates mapped to the assembly of the sequence from the watermelon isolate. Scale bars represent divergence in the number of single nucleotide polymorphisms.

gastroenteritis linked to consumption of watermelon imported from Brazil.

Molecular analysis determined the contaminated watermelon strain and human isolates from confirmed cases in the UK, Ireland and Germany indistinguishable from one another by PFGE and, for a subset, by WGS. In this outbreak investigation, epidemiological studies were successfully informed by analyses of PFGE data. The source of infection was confirmed through standard food traceback investigations. We used this opportunity to examine and evaluate the use of WGS for the purposes of food-borne outbreak investigation. We found that using WGS data, we were able to describe with greater clarity the relatedness of strains isolated from cases and watermelons and also demonstrate the scale of difference between these organisms and other $S$. Newport strains concurrently circulating in Europe. While it could be deduced from the traceback investigations that the outbreak strain was not European in origin, the WGS data provided objective evidence to confirm the scale of genetic difference between 
imported and indigenous strains. Understanding these effects should help inform future food-borne outbreak investigations where WGS data analyses could be used to provide important clues as to the geographic origins of implicated food vehicles, which in turn could feed back into hypothesis generation.

As costs decline, and the speed and fidelity of sequencing improve, WGS is becoming an increasingly accessible element of public health microbiology. It has been postulated that WGS may soon replace conventional typing in the investigation and management of outbreaks [11]. WGS can provide a level of evidence of linkage between specific sources of infection and human cases that is close to irrefutable. In view of the sensitivity of reputation for food business operators and foodproducing countries, this level of evidence is important in gaining support for intervention measures to protect public health. Furthermore, as genome databases of major food-borne pathogens expand it is reasonable to expect detection of previously unrecognised links between cases of infection and complex food chains. The challenge for public health microbiology laboratories is to achieve the capacity for rapid sequence determination, data storage and analysis that will allow full exploitation of this powerful new approach [12].

Traceback investigations identified Brazilian watermelons as a common factor in cases associated with the outbreak. Consumption of watermelon was reported by a high proportion of cases across all six countries as compared to the general population [2]. The German convenience sample also indicated a higher level of consumption of watermelon in outbreak cases than their controls. However, recall and selection bias may have led to some underestimation of consumption in the study population.

Cases occurred over a number of weeks and, as identified by traceback, storage and distribution of watermelon spans several weeks. Cases declined in February, coinciding with the end of the Brazilian watermelon importation season. The UK Department for Environment, Food and Rural Affairs Statistics team and the Rural Payment Agency's Horticultural Marketing Inspectorate indicated that the season for imported Brazilian watermelons runs from August to February in the UK.

The same melon grower was associated with the contaminated watermelon slice and human cases in Ireland and Germany. The melons associated with the Scottish cases were traced back to a different grower in the same region. However, the isolates from Scottish cases shared a common sequence with the other cases, therefore it is likely that Brazilian watermelons from a particular area were the vehicle, but that these were not confined to one specific grower.

Cases reported consumption of watermelons whole, pre-packaged and sliced, alone, or as part of fruit salads or melon mixtures, indicating the melons themselves were contaminated and contamination did not occur during processing. Furthermore, different retailers, with different importers, processors and distributors were reported, also precluding these as the source of contamination. It is not possible to confirm at what point contamination occurred but there is likely to have been a common source of $S$. Newport which contaminated the produce at an unidentified point between growing and distribution.

In the United States (US) and Canada, melons have consistently been linked to outbreaks of Salmonella [13-17]. Three multistate outbreaks of S. Poona infection associated with eating cantaloupe melons imported from Mexico occurred in three consecutive years during the spring of 2000, 2001 and 2002 [18]. In 2011, in the US, a multistate outbreak of $S$. Panama linked to cantaloupe melons harvested in Guatemala occurred between February and April [19]. Outbreaks of salmonellosis linked to melons have also occurred in Australia in 2006 and New Zealand in 2009 [20-21].

This is the first outbreak of salmonellosis in Europe associated with melons from South America. Given that this is a ready-to-eat product, and that salmonellae have the ability to attach to or enter into vegetables and fruits, it is likely that these produce items are potential sources for future outbreaks of salmonellosis [15]. The watermelon market has been developed by Brazil in recent years and Brazilian exports to the UK have been around 6,000 tonnes per annum in recent years. Brazil also exports similar quantities to Germany and the Netherlands [data not shown].

Recurrent outbreaks such as the one described here highlight the importance of good agricultural practices and hygiene manufacturing controls from the grower to the consumer. As a consequence of repeated RASFF notifications dealing with contaminated watermelons from Brazil, $10 \%$ of shipments of watermelons imported from Brazil into the European Union have been tested for Salmonella since January 2013 [22].

The use of standardised case exposure questionnaires and the use of PFGE and WGS to recognise outbreaks more easily, would improve both their timely detection and control. Our use of genome sequencing information and PFGE demonstrated the ability of these techniques to unequivocally link cases which would have been impossible to connect using limited available traceback information. Informal (PulseNet International, EPIS) and formal (European Early Warning and Response System and RASFF) communication platforms enabled the full geographical extent of the outbreak to be rapidly recognised and exemplify their use as valuable media for informing public health experts. International trade in food will always provide the opportunity for infections to appear far from the source of contamination. We have the tools to identify and respond to such outbreaks and their use should be maximised. 


\section{Acknowledgements}

In addition to all members of the outbreak control team, the OCT in Germany would like to thank local and state health and food safety authorities for their support. We would like to thank microbiologists and staff from the HPA Gastrointestinal Bacteria Reference Unit and the Scottish Salmonella, Shigella and Clostridium difficile Reference Laboratory and also the patients for their collaboration in providing data.

The sequencing work in this paper was supported by Wellcome Trust grant WTo76964 through funding from The Wellcome Trust Sanger Institute

\section{Conflict of interest}

None declared.

\section{Authors' contributions}

LB: managed data collection and collation for cases in England, Wales and Northern Ireland and wrote the draft manuscript. IF: coordinated the local public health response, contributed to data collation, read and revised the draft manuscript and approved the final version. TP: was responsible for molecular analysis and interpretation of laboratory results for isolates from England, Wales and Northern Ireland, reviewed the manuscript and approved the final version. AM and NT: Designed and performed phylogenetic analysis and provided results, contributed to drafting the manuscript, made revisions, and approved the final version. $\mathrm{HB}$ and BR: were the principle investigators in Germany and made substantial contributions to study conception and design, data collection, analysis and interpretation. Both critically revised the manuscript and approved the final version. PM: collected data in Ireland and coordinated the Irish public health response. $M C$ performed laboratory testing in Ireland, read and revised the manuscript. JC: collected and co-ordinated data from Scotland and contributed to the public health response. VA assisted in study design and undertook data collection. CL contributed to study design, coordinated the initial UK public health response, and critically reviewed the manuscript.

\section{International Outbreak Control Team}

Joanne Aish, Goutam Adak, Victor Aiyedun, Derek Brown, Lynda Browning, Paul Cook, Cecilia Ellis, Andrew Fox, Elizabeth de Pinna, Patricia Garvey, Kathie Grant, Dorothy Guina-Dornan, Petra Hiller, Colin Houston, Naomi Launders, Burkhard Malorny, Brendan O’Brien, Beatrice Pfefferkorn, Rita Prager, Wolfgang Rabsch, Roland Salmon, Robert Smith, Brian Smyth, Kirsten Stone and Heidi Wichmann-Schauer.

\section{References}

1. Rapid Alert System for Food and Feed (RASFF). Brussels: European Commission. [Accessed: 1 Aug 2014]. Available from: http://ec.europa.eu/food/safety/rasff/portal/index_en.htm

2. Whitton C, Nicholson SK, Roberts C, Prynne CJ, Pot GK, Olson A, et al. National Diet and Nutrition Survey: UK food consumption and nutrient intakes from the first year of the rolling programme and comparisons with previous surveys. Br J Nutr. 2011:106(12):1899-914. http://dx.doi.org/10.1017/ So007114511002340

3. Grimont PAD, Weill FX. Antigenic formulas of the Salmonella serovars. 9th ed. Paris: World Health Organization Collaborating Centre for Reference and Research on Salmonella, Institut Pasteur; 2007. Available from: http:// www.pasteur.fr/ip/portal/action/WebdriveActionEvent/ oid/01s-000036-089
4. Frost JA. Testing for resistance to antimicrobial drugs. In: Chart $\mathrm{H}$, editor. Methods in practical laboratory bacteriology. New York: CRC Press; 1994. pp. 73-82.

5. Browning LM, Brown DJ, Coia JE, Cowden JM, Mather $\mathrm{H}$. Antimicrobial resistance of Salmonella in Scotland, 2005 (excluding S. Typhi and S. Paratyphi). HPS Weekly Report. 2007;21 (41):172. Accessed 1 Aug 2014. Available from: http:// www.documents.hps.scot.nhs.uk/ewr/pdf2007/0721.pdf

6. Peters TM, Berghold C, Brown D, Coia J, Dionisi AM, Echeita $A$, et al. Relationship of pulsed-field profiles with key phage types of Salmonella enterica serotype Enteritidis in Europe: results of an international multi-centre study. Epidemiol Infect. 2007;135(8):1274-81. http://dx.doi.org/10.1017/ So950268807008102

7. Wellcome Trust Sanger Institute (WTSI). SMALT. Hinxton: WTSI. [Accessed: 1 Aug 2014]. Available from: http://www.sanger. ac.uk/resources/software/smalt/

8. Harris SR, Feil EJ, Holden MT, Quail MA, Nickerson EK, Chantratita N, et al. Evolution of MRSA during hospital transmission and intercontinental spread. Science. 2010;327(5964):469-74. http://dx.doi.org/10.1126/ science.1182395

9. Stamatakis A. RAxML-VI-HPC: maximum likelihood-based phylogenetic analyses with thousands of taxa and mixed models. Bioinformatics. 2006;22(21):2688-90. http://dx.doi. org/10.1093/bioinformatics/btl446

10. Zerbino DR, Birney E. Velvet: algorithms for de novo short read assembly using de Bruijn graphs. Genome Res. 2008;18(5):821-9. http://dx.doi.org/10.1101/gr.074492.107

11. Sabat AJ, Budimir A, Nashev D, Sá-Leão R, van Dijl JM, Laurent F, et al. Overview of molecular typing methods for outbreak detection and epidemiological surveillance. Euro Surveill. 2013;18(4): $\mathrm{pii}=20380$

12. Achtman M, Wain J, Weill F-X, Nair S, Zhou Z, Sangal V, et al. Multilocus Sequence Typing as a Replacement for Serotyping in Salmonella enterica. PLoS Pathog. 2012;8(6):e1002776. http:// dx.doi.org/10.1371/journal.ppat.1002776

13. Bowen A, Fry A, Richards G, Beuchat L. Infections associated with cantaloupe consumption: a public health concern. Epidemiol Infect. 2006;134(4):675-85. http://dx.doi. org/10.1017/So950268805005480

14. Gayler GE, MacCready RA, Reardon JP and McKernan BF. An outbreak of salmonellosis traced to watermelon. Public Health Rep. 1955:70(3):311-3. http://dx.doi.org/10.2307/4589055

15. Hanning IB, Nutt JD, Ricke SC. Salmonellosis outbreaks in the United States due to fresh produce: sources and potential intervention measures. Foodborne Pathog Dis. 2009;6(6):63548. http://dx.doi.org/10.1089/fpd.2008.0232

16. Blostein J. An outbreak of Salmonella Javiana associated with consumption of watermelon. J Environ Health. 1993;56(1):29-31.

17. Centers for Disease Control and Prevention (CDC). Foodborne outbreak online database (FOOD). Atlanta: CDC. [Accessed: 1 Aug 2014]. Available from: http://wwwn.cdc.gov/ foodborneoutbreaks/Default.aspx

18. Centers for Disease Control and Prevention (CDC). Multistate outbreaks of Salmonella serotype Poona infections associated with eating cantaloupe from Mexico--United States and Canada, 2000-2002. MMWR Morb Mortal Wkly Rep. 2002;51(46):1044-7.

19. Centers for Disease Control and Prevention (CDC).Investigation update: Multistate outbreak of Salmonella Panama infections linked to cantaloupe. Atlanta: CDC; 2011. Available from: http://www.cdc.gov/salmonella/panama0311/062311/index. html

20. Munnoch SA, Ward K, Sheridan S, Fitzsimmons GJ, Shadbolt CT, Piispanen JP, et al. A multi-state outbreak of Salmonella Saintpaul in Australia associated with cantaloupe consumption. Epidemiol Infect. 2009;137(3):367-74. http:// dx.doi.org/10.1017/So950268808000861

21. McCallum L, Torok M, Dufour MT, Hall A, Cramp G. An outbreak of Salmonella Typhimurium phage type 1 associated with watermelon in Gisborne, January 2009. N Z Med J. 2010;123(1322):39-45.

22. European Commission. Commission Implementing Regulation (EU) No 1235/2012 of 19 December 2012 amending Annex I to Regulation (EC) No 669/2009 implementing Regulation (EC) No $882 / 2004$ of the European Parliament and of the Council as regards the increased level of official controls on imports of certain feed and food of non-animal origin. Brussels: European Commission; 2012. L 350/44-50. Available from: http://eur-lex. europa.eu/LexUriServ/LexUriServ.do?uri=0J:L:2012:350:0044 :0050:EN:PDF 